\title{
A Study on Anthropometric Measurements, Blood Pressure, Blood Sugar and Food Intakes Among Different Social Status and Ethnicities
}

\author{
Sima Jafarirad, ${ }^{1,2}$ Aghdas Mousavi Borazjani, ${ }^{2}$ Mojdeh Fathi, ${ }^{2}$ and Razie Hormoznejad ${ }^{2,}$ \\ ${ }^{1}$ Nutrition and Metabolic Disease Research Center, Ahvaz Jundishapur University of Medical Sciences, Ahvaz, IR Iran \\ ${ }^{2}$ Department of Nutrition, School of Paramedicine, Ahvaz Jundishapur University of Medical Sciences, Ahvaz, IR Iran \\ "Corresponding author: Razie Hormoznejad, Department of Nutrition, School of Paramedicine, Ahvaz Jundishapur University of Medical Sciences, Ahvaz, IR Iran. Tel: \\ +98-6133738317, Fax: +98-6133738330, E-mail: r_hormozi68@yahoo.com
}

Received 2016 May 06; Revised 2016 June 10; Accepted 2016 June 20.

\begin{abstract}
Background: Metabolic syndrome is a disorder that increases the risk of cardiovascular disease and diabetes.

Objectives: The aim of the study was to evaluate some risk factors of the metabolic syndrome and food intakes among people who lived in Ahvaz City, Iran.

Methods: It was a filed study that was conducted on 211 subjects who participated in health exhibition. Socioeconomic status and ethnicity were asked by a general questionnaire. Weight, height, body mass index, waist circumference (WC) and WC to hip circumference ratio (WHR) were obtained. Blood sugar was measured by a glucometer. Systolic and diastolic blood pressures were obtained and dietary intakes were assessed by a brief instrument.

Results: There was a significant difference in weight, height, WC, WHR and systolic blood pressure among different jobs. Workers had more intakes of cake and sweets. Arab subjects had more intakes of bread and fishes and Persians more intakes of vegetables. Soda, chocolate and candy were more consumed by Kurd ethnicity.

Conclusions: Job may be accounted as an important effective socioeconomic factor related to metabolic syndrome risk factors; also different cultures due to different ethnicities may have an influence on lifestyle and dietary intakes.
\end{abstract}

Keywords: Anthropometric Measurements, Blood Pressure, Blood Glucose, Dietary Intake, Social Class, Ethnic Groups

\section{Background}

The prevalence of noncommunicable diseases is increasing and it indicates the presence of epidemiological and nutritional transitions. Metabolic syndrome is an important noncommunicable disorder and its increasing rate has been shown in countries with low to middle social and economic strata (1). This syndrome is a cluster of conditions including excess body fat around the waist, a high blood glucose level, dyslipidemia, and high blood pressure. Metabolic syndrome increases the risk of diabetes type 2 and cardiovascular diseases $(2,3)$, two major noncommunicable diseases in the world.

There are some evidences that social and economic factors have influence on some chronic diseases like cardiovascular diseases and diabetes (4-6). Social factors are defined as social life and work conditions, these conditions could be affected by distribution of wealth and power, global and national income (7). A study in China showed the higher risk of metabolic syndrome in women with lower education and monthly income, but male subjects did not reveal this relationship (8). Moreover, some studies that were conducted about the relationship between cardiovascular diseases and socioeconomic status reported a higher prevalence of cardiovascular disease in developed countries (9-11). It seems that the study of the relationship between the socioeconomic factors and metabolic syndrome, cardiovascular disease or diabetes in developing countries has a great importance because these countries experience nutritional transition.

Studies on the relationship between ethnicity and metabolic syndrome reported that either all ethnic groups or individuals within the same ethnic group are not affected in the same way. One study in Malaysia showed a significant difference in the prevalence of the metabolic syndrome among different ethnics; ethnic Chinese had the lowest prevalence of the metabolic syndrome, while ethnic Indians had the highest (12). In Iran, researches indicated a high prevalence of the metabolic syndrome among women; this prevalence in both sexes was higher compared with some European countries such as France (13). The results of another study in Iran showed higher food insecurity among people with the metabolic syndrome and they reported some socioeconomic factors related to food insecurity, such as monthly income, family number and the economical level of family (14).

According to the increasing rate of the metabolic syndrome and lack of the studies about the relationship of 
socioeconomic factors and ethnicity with risk factors of the metabolic syndrome in Iran, this cross-sectional and field study was conducted on a sample of people residing in Ahvaz city, Iran, to investigate some risk factors of the metabolic syndrome (such as blood pressure, waist circumference (WC) and blood sugar) in different social and ethnic groups. The interesting point of this study was that healthy apparent people were studied and it was important because they did not refer to hospital or health services.

\section{Objectives}

Also, in this study, dietary intakes were studied as an important lifestyle factor related to the metabolic syndrome

\section{Methods}

This cross-sectional study was conducted on people residing in Ahvaz city, Iran, who participated in health exhibition and visited the nutrition station. This exhibition was held by corporation of cultural and social affairs of Ahvaz municipality and Red Crescent society for one week. The study protocol conforms to the ethical guidelines of the 2008 Declaration of Helsinki and an informed written consent was obtained from all the participants. The subjects were informed of the objectives of the study and were free to leave the study at any time. The inclusion criterion was age ranges between 20 and 70 years, and exclusion criterion was past medical history (including major illnesses, myocardial infraction, stroke, any previous surgery/operations, or other severe diseases). From people who visited the nutrition station, 211 subjects agreed to participate the study. All of them completed a consent form. The participants were asked to answer general questionnaire included information about age, gender, ethnicity, job, level of education, marital status, number of family members and spouse's job and education. Also, familial history of chronic diseases and physical activity were asked. Anthropometric indices, including weight, height, body mass index (BMI), WC, hip circumference (HC) and WC to HC ratio (WHR) were also measured. All of measurements were done by one person to minimize the individual error. Height was measured when subjects' shoes were off, facing directly ahead and arms by the sides. Also, subjects' heels, buttocks and upper back were in contact with the wall when the height measurement was made. The weight was measured using Seca scale to the nearest 0.1 $\mathrm{kg}$ (it was calibrated before using). The body mass index was calculated using the following formula: weight in kilograms divided by height squared in meters. To measure the WC, a nonelastic tape (sensitivity 0.1 centimeter) was placed around the abdomen at the level of midway point between the uppermost border of the iliac crest and the lower border of the costal margin (rib cage) and a reading taken when the tape was snug but did not compress the skin. The hip circumference was measured when subjects had stood with feet fairly close together. Tape was placed in the position around the maximum circumference of the buttocks. To determine WHR, WC was divided by HC. Blood pressure was taken from the left arm, which was flexed at the elbow and supported at the heart level by an aneroid manometer in the sitting position on the chair.

To measure the randomized blood sugar, a blood glucometer (EasyGluco, South Korea) was used. Before using, it was calibrated by inserting a test strip. Following the manufacturer's instructions to prepare the lancing device, a drop of blood was gotten from the side of subjects' fingertip. Then blood sugar was measured by touching and holding the test strip opening to the drop until it had absorbed enough to begin the test. The levels of randomized blood sugar for healthy, prediabetic and diabetic adults were considered $79-140 \mathrm{mg} / \mathrm{dL}, 140$ - $200 \mathrm{mg} / \mathrm{dL}$ and more than $200 \mathrm{mg} / \mathrm{dL}$, respectively (15).

A food frequency brief instrument was used to determine food intakes. This brief instrument included 25 kinds of foods that were classified in eight following groups according to food pyramid: bread and grain (bread, rice and pasta), meat and the alternatives (meat, chicken, fish, egg and legume), milk and dairy products (milk, yogurt, Iranian yogurt drink (doogh) and cheese), different kinds of vegetables, different kinds of fruits, cake and sweets, fast foods and drinks. The validity and reliability of this questionnaire were shown in some studies $(16,17)$. Subjects reported their serving intakes per day of each food during six months pass.

Data were analyzed using SPSS version 17.0. Chisquared test was used to determine whether there was a significant difference between the expected frequencies and the observed frequencies in one or more categories. Quantitative variables were shown by mean \pm standard deviation (SD). One-way AVOVA was used to compare the mean of each quantitative variable among different groups.

\section{Results}

This study was conducted on 211 subjects who was resident in Ahvaz city, 152 males (72\%) and 52 females (28\%). Males had more systolic blood pressure compared to females, (124.8 \pm 11.1 and $116.9 \pm 13$, respectively; $\mathrm{P}<0.001$ ); also, this significant difference was seen for diastolic blood pressure (78.6 \pm 6.1 and $74.5 \pm 8.1$, respectively; $\mathrm{P}<0.001)$, 
but the means of blood pressure in both sexes were normal. There was no significant difference in blood sugar between males and females $(117.1 \pm 50.3$ and $114.2 \pm 58.8$, respectively).

Anthropometric measurements were assayed in all participants. Table 1 shows the mean \pm standard deviation (SD) of anthropometric measurements in different degrees of education, job and ethnicity. BMI had significant difference between different degrees of education. Weight, height, WC and WHR had significant differences in different jobs (Table 1). Self-employed subjects had more weight, and a Tukey post-hoc analysis showed this difference between the self-employed with jobless $(\mathrm{P}<0.001)$, and employee $(\mathrm{P}=0.026)$. The waist circumference was higher in self-employed compared to jobless (Tukey post-hoc analysis, $\mathrm{P}=0.009$ ). Higher WHR was seen in those who were worker and lower WHR in high-ranking employee, and the post- hoc analysis displayed the difference between jobless and worker $(\mathrm{P}=0.009)$, jobless and employee $(\mathrm{P}=<0.001)$, and jobless and self-employed $(\mathrm{P}=0.008)$.

Among different anthropometric measurements, height showed significant differences in different ethnicities (Table 1). Statistical analysis confirmed the difference between Persian and Arab ( $\mathrm{P}<0.001)$, Persian and Lor, Lak and Bakhtiyari $(\mathrm{P}<0.001)$.

Blood sugar, systolic and diastolic blood pressure had no significant differences in various degrees of education and ethnicities (Table 2). Systolic blood pressure showed a significant difference in different jobs and the Tukey analysis confirmed the difference between employee and jobless $(\mathrm{P}=0.025)$.

Food intakes in different degrees of education have been shown in Table 3. Only vegetable intake had a significant difference. Interestingly, the post- hoc analysis declared this difference between illiterate with under diploma ( $\mathrm{P}=0.019)$, diploma $(\mathrm{P}<0.001)$, associate and bachelor $(\mathrm{P}<0.001)$, Master of sciences and above $(\mathrm{P}=$ 0.05).

Food intakes were studied in different jobs too (Table 4). Among different kinds of food groups, only intakes of cake and sweets were different; the Tukey analysis confirmed this difference between worker and jobless.

Different ethnicities had various intakes of some foods. Significant differences of food intakes were shown for bread, fish, vegetables, soda, chocolate and candy (Table 5). The Tukey analysis displayed different intakes of bread between Arab with Persian $(\mathrm{P}<0.001)$, and Arab with Lor, Lak and Bakhtiyari $(\mathrm{P}<0.001)$. The results showed different intakes of vegetables between Persian and Lor, Lak and Bakhtiyari $(\mathrm{P}=0.024)$. Arab ethnicity had more intake of fish compared to Persian $(\mathrm{P}=0.019)$ and Lor, Lak and Bakhtiyari $(\mathrm{P}=0.016)$.

\section{Discussion}

This study was conducted on subjects who residing in Ahvaz, with different ethnicities and socioeconomic status (SES). Weight, WC and systolic blood pressure showed significant differences in different jobs. Also, the results confirmed that workers had more consumption of cake and sweet. In different levels of education, blood sugar was higher in a trend of significance in subjects who were illiterate. Some studies showed that SES, (such as kind of job and level of education) was associated with a higher risk of the metabolic syndrome. In Portugal, Santos et al. (18) showed different frequencies of WC, blood pressure and high fasting blood glucose in different groups of job. Another study in China showed the effect of sex on the relationship between SES and the metabolic syndrome; the authors confirmed that the levels of household income per month were associated with a higher risk of the metabolic syndrome among women not in men (8). Also, a research that was conducted on Korean adults confirmed the relationship of a lower education level and personal income with a higher risk of the metabolic syndrome in women (19). Moreover, Mangat et al. (20) reported a significant correlation between higher SES and sedentary jobs and metabolic syndrome in North India. The results of other population-based cross-sectional study on males in British towns confirmed that adult and childhood social classes were both inversely related to the metabolic syndrome(21). In our study, females' participation was less than males; so, SES was studied overall in both sexes. In the present study, the effect of job on the metabolic syndrome risk factors such as weight, WC and systolic blood pressure were more than the education level. Although education is a good indicator of social class, it seems that the effect of education is appeared in occupation and income levels. So possibly, the indirect effect of education was the reason for its less association with risk factors of the metabolic syndrome in the present study. In many developing countries, socioeconomic determinants of the metabolic syndrome are not considered as a preventative healthcare system. According to the importance of these parameters, it is suggested that the healthcare system should consider these factors in the preventive programs.

In the present study, there was no significant difference between the metabolic syndrome risk factors and ethnicity, but the interesting finding was difference in the intake of some foods among Iranian ethnicities. In Asia, a study that was conducted on Malaysians adults revealed that the prevalence of the metabolic syndrome was higher among Indians compared to Indigenous Sarawakians, Malays and Chinese (12). A study in the United States on adolescent students showed Hispanics had high abdominal adipos- 
Table 1. Mean (SD) Values of Anthropometric Measurements in Different Degrees of Education, Job and Ethnicity

\begin{tabular}{|c|c|c|c|c|c|c|}
\hline & Weight, kg & Height, $\mathrm{cm}$ & BMI, $\mathrm{kg} / \mathrm{m}^{2}$ & WC, $\mathbf{c m}$ & $\mathrm{HC}, \mathrm{cm}$ & WHR, Ratio \\
\hline \multicolumn{7}{|l|}{ Degree of education } \\
\hline Illiterate & $77.5 \pm 15.2$ & $167.9 \pm 12.6$ & $27.5 \pm 4.3$ & $91.7 \pm 15.6$ & $104.9 \pm 14.7$ & $0.88 \pm 0.15$ \\
\hline Under diploma & $78.6 \pm 16$ & $170.1 \pm 9.7$ & $27.2 \pm 5.6$ & $91.4 \pm 13.1$ & $102.6 \pm 14.9$ & $0.89 \pm 0.11$ \\
\hline Diploma & $81.3 \pm 13.4$ & $170.1 \pm 8.5$ & $28.1 \pm 4.2$ & $93.8 \pm 10.1$ & $105.8 \pm 8.2$ & $0.88 \pm 0.07$ \\
\hline Associate and Bachelor & $76.4 \pm 17.3$ & $173.2 \pm 8.25$ & $25.4 \pm 5.1$ & $88.6 \pm 1.4$ & $101.9 \pm 10.3$ & $0.87 \pm 0.08$ \\
\hline Master and above & $72.4 \pm 15.6$ & $169.2 \pm 10.7$ & $25.1 \pm 4$ & $86.5 \pm 9.9$ & $100.9 \pm 8.6$ & $0.85 \pm 0.07$ \\
\hline Pvalue $^{\mathrm{a}}$ & 0.469 & 0.108 & $0.044 \#$ & 0.177 & 0.492 & 0.426 \\
\hline \multicolumn{7}{|l|}{ Job } \\
\hline Jobless & $72.9 \pm 13.9$ & $165.8 \pm 11.6$ & $26.7 \pm 5.4$ & $86.9 \pm 13$ & $104.1 \pm 13.5$ & $0.84 \pm 0.10$ \\
\hline Worker & $76.9 \pm 13.5$ & $174.3 \pm 7.4$ & $25.2 \pm 3.8$ & $90.4 \pm 7.4$ & $96.6 \pm 9.8$ & $0.94 \pm 0.08$ \\
\hline Employee & $77.0 \pm 16.5$ & $172.1 \pm 7.7$ & $26.0 \pm 5$ & $90.8 \pm 11.1$ & $101.1 \pm 11.3$ & $0.90 \pm 0.09$ \\
\hline High-ranking employee & $74.0 \pm 18.5$ & $169.4 \pm 9.6$ & $25.4 \pm 3.4$ & $89.2 \pm 8.3$ & $108.2 \pm 2.2$ & $0.82 \pm 0.06$ \\
\hline Self-employed & $85.0 \pm 15.8$ & $175.2 \pm 5.5$ & $27.7 \pm 5.2$ & $94.2 \pm 12.6$ & $105.1 \pm 11.2$ & $0.89 \pm 0.08$ \\
\hline Pvalue $^{\mathrm{a}}$ & $0.001^{b}$ & $0.001^{\mathrm{b}}$ & 0.296 & $0.027^{\mathrm{b}}$ & 0.083 & $0.001^{\mathrm{b}}$ \\
\hline \multicolumn{7}{|l|}{ Ethnicity } \\
\hline Lor, Lak, Bakhtiyari & $81.1 \pm 16.8$ & $172.5 \pm 8.5$ & $27.2 \pm 5.4$ & $91.8 \pm 12.8$ & $103.6 \pm 12.2$ & $0.89 \pm 0.09$ \\
\hline Turk & $78.40 \pm 14.7$ & $172.5 \pm 10$ & $26.3 \pm 4.3$ & $90.4 \pm 10.5$ & $104.2 \pm 11.2$ & $0.87 \pm 0.06$ \\
\hline Kurd & $68.3 \pm 4.0$ & $168.6 \pm 5.8$ & $24.1 \pm 2.2$ & $80.7 \pm 11.2$ & $90.4 \pm 17.1$ & $0.9 \pm 0.12$ \\
\hline Arab & $78.3 \pm 17.3$ & $173.0 \pm 8.8$ & $26.2 \pm 5.6$ & $91.1 \pm 12.3$ & $102.7 \pm 12.8$ & $0.89 \pm 0.1$ \\
\hline Persian & $73.5 \pm 12.5$ & $165.8 \pm 9.9$ & $26.8 \pm 4.1$ & $89.0 \pm 10.7$ & $104.1 \pm 8.1$ & $0.85 \pm 0.08$ \\
\hline Pvalue $^{\mathrm{a}}$ & 0.066 & $0.001^{\mathrm{b}}$ & 0.509 & 0.176 & 0.073 & 0.259 \\
\hline
\end{tabular}

${ }^{\mathrm{a}}$ Chi-square statistical analysis.

${ }^{\mathrm{b}}$ Significance level $<0.05$.

ity and high triglycerides (22). Also, other study in this country confirmed that Hispanics and blacks had higher WC than whites (23). Different rates of the metabolic syndrome among various ethnicities maybe accounted as a result of different lifestyles and food intakes. Data from the national health and nutrition examination survey, 2009 to 2010, showed that non-Hispanic black adults consume significantly less dietary fiber compared with other ethnic groups (24). When the diets of African American and Hispanic families in the Special Supplemental Nutrition Program for women, infants, and children (WIC) were compared, diets of Hispanic mothers and children were lower in percentage of calories from fat, added sugars, sodium, and sweetened beverages, but higher in fruit, total dairy, and whole grains compared to African American (25). Sluyter et al. (26) compared food intakes of European, Asian, Pacific Island and Maori adolescents and resulted Europeans ate the fewest eggs, and Asians and Pacific Islanders ate more servings of chicken and fish, and fewer servings of cereal and milk than Europeans. Differences of dietary intakes among various ethnicities could be accounted as important indices that have a significant effect on some metabolic syndrome parameters, as a study confirmed that the intake of sweetened drinks was lower in subjects who had no risk factors than in subjects who had 1 - 2 risk factors among whites but not among African Americans (27). Although there was no significant relationship between ethnicity and the metabolic syndrome risk factors in this study, more intakes of some foods such as soda, cake, sweet and chocolate among some ethnicities showed the importance of cultural and lifestyle parameters. So, it is better these differences be considered when the metabolic syndrome is assessed among different ethnicities.

Lipid profile was not measured in this study because it was a field study; so, it can be considered as a limitation of the study. Although blood sugar was assessed in this study, fasting blood sugar is more valuable. The importance of this research was the study of metabolic syndrome risk fac- 
Table 2. Mean (SD) Values of Blood Sugar and Blood Pressure in Different Degrees of Education, Job and Ethnicity

\begin{tabular}{|c|c|c|c|}
\hline & Blood Sugar, mg/dL & Systolic Blood Pressure & Diastolic Blood Pressure \\
\hline \multicolumn{4}{|l|}{ Degree of education } \\
\hline Illiterate & $150.9 \pm 108.6$ & $127.3 \pm 13.7$ & $80.7 \pm 4.6$ \\
\hline Under diploma & $119.6 \pm 65.9$ & $121.6 \pm 11.9$ & $77.3 \pm 6.6$ \\
\hline Diploma & $108.1 \pm 36.75$ & $123.6 \pm 11.2$ & $78.4 \pm 5.9$ \\
\hline Associate and Bachelor & $112.6 \pm 25.2$ & $122.4 \pm 11.7$ & $76.7 \pm 7.3$ \\
\hline Master and above & $101.3 \pm 18.9$ & $119.4 \pm 19.1$ & $75.7 \pm 11.5$ \\
\hline Pvalue $^{\mathrm{a}}$ & 0.066 & 0.481 & 0.214 \\
\hline \multicolumn{4}{|l|}{ Job } \\
\hline Jobless & $115.9 \pm 57.5$ & $119.8 \pm 11.8$ & $76.5 \pm 7.7$ \\
\hline Worker & $124.6 \pm 79.7$ & $120.4 \pm 12.1$ & $76.4 \pm 8.1$ \\
\hline Employee & $120.5 \pm 58.2$ & $125.3 \pm 13.2$ & $77.3 \pm 6.9$ \\
\hline High-ranking employee & $104.0 \pm 18.0$ & $120.0 \pm 8.4$ & $72.0 \pm 8.4$ \\
\hline Self-employed & $107.5 \pm 32.3$ & $124.1 \pm 10.2$ & $79.3 \pm 5.3$ \\
\hline Pvalue $^{a}$ & 0.802 & $0.008^{b}$ & 0.073 \\
\hline \multicolumn{4}{|l|}{ Ethnicity } \\
\hline Lor, Lak, Bakhtiyari & $109.1 \pm 18.4$ & $122.6 \pm 12.8$ & $76.6 \pm 7.8$ \\
\hline Turk & $123.5 \pm 61.5$ & $126.8 \pm 16.2$ & $78.2 \pm 6.0$ \\
\hline Kurd & $132.9 \pm 49.2$ & $120.0 \pm 11.5$ & $75.7 \pm 4.5$ \\
\hline Arab & $119.8 \pm 62.2$ & $122.8 \pm 11.2$ & $78.6 \pm 6.2$ \\
\hline Persian & $117.5 \pm 68.4$ & $121.7 \pm 12.2$ & $76.9 \pm 7.2$ \\
\hline Pvalue $^{a}$ & 0.632 & 0.475 & 0.969 \\
\hline
\end{tabular}

a One-way ANOVA.

${ }^{\mathrm{b}}$ Significance level $<0.05$.

tors and food intakes among different Iranian ethnicities.

\subsection{Conclusion}

Different ethnicities have various cultures. According to the results, it is better to mention socioeconomic status and cultural varieties in health programs to manage better lifestyle and reduce the risk factors of the metabolic syndrome.

\section{Acknowledgments}

This study was supported by Red Crescent Society of Ahvaz city with corporation of cultural and social affairs of Ahvaz Municipality. The authors wish to thank all the participants in this study.

\section{References}

1. Cherry CO, Serieux E, Didier M, Nuttal ME, Schuster RJ. Prevalence of risk factors for the metabolic syndrome in the middle income
Caribbean nation of st. Lucia. Adv Prev Med. 2014;2014:501972. doi: 10.1155/2014/501972. [PubMed: 25309758].

2. Kazlauskiene L, Butnoriene J, Norkus A. Metabolic syndrome related to cardiovascular events in a 10-year prospective study. Diabetol Metab Syndr. 2015;7:102. doi: 10.1186/s13098-015-0096-2. [PubMed: 26594246].

3. Zadhoush F, Sadeghi M, Pourfarzam M. Biochemical changes in blood of type 2 diabetes with and without metabolic syndrome and their association with metabolic syndrome components. J Res Med Sci. 2015;20(8):763-70. doi: 10.4103/1735-1995.168383. [PubMed: 26664424].

4. Tao X, Li J, Zhu X, Zhao B, Sun J, Ji L, et al. Association between socioeconomic status and metabolic control and diabetes complications: a cross-sectional nationwide study in Chinese adults with type 2 diabetes mellitus. Cardiovasc Diabetol. 2016;15:61. doi: 10.1186/s12933-0160376-7. [PubMed: 27048217].

5. Alves J, Nunes C, Perelman J. Socio-economic inequalities in tobaccorelated diseases in Portugal: an ecological approach. Public Health. 2016;130:36-42. doi: 10.1016/j.puhe.2015.08.008. [PubMed: 26427313].

6. Li JB, Wang X, Zhang JX, Gu P, Zhang X, Chen CX, et al. Metabolic syndrome: prevalence and risk factors in southern China.J Int Med Res. 2010;38(3):1142-8. [PubMed: 20819453].

7. Lang T, Lepage B, Schieber AC, Lamy S, Kelly-Irving M. Social determinants of cardiovascular diseases. Public Health Reviews. 2012;33(2):601-22. 
8. Zhan Y, Yu J, Chen R, Gao J, Ding R, Fu Y, et al. Socioeconomic status and metabolic syndrome in the general population of China: a crosssectional study. BMC Public Health. 2012;12:921. doi: 10.1186/1471-245812-921. [PubMed: 23110697].

9. Moreira GC, Cipullo JP, Ciorlia LA, Cesarino CB, Vilela-Martin JF. Prevalence of metabolic syndrome: association with risk factors and cardiovascular complications in an urban population. PLoS One. 2014;9(9):105056. doi: 10.1371/journal.pone.0105056. [PubMed: 25180496].

10. Capingana DP, Magalhaes P, Silva AB, Goncalves MA, Baldo MP, Rodrigues SL, et al. Prevalence of cardiovascular risk factors and socioeconomic level among public-sector workers in Angola. BMC Public Health. 2013;13:732. doi:10.1186/1471-2458-13-732. [PubMed: 23924306].

11. Wu SH, Woo J, Zhang XH. Worldwide socioeconomic status and stroke mortality: an ecological study. Int J Equity Health. 2013;12:42. doi: 10.1186/1475-9276-12-42. [PubMed: 23767844].

12. Rampal S, Mahadeva S, Guallar E, Bulgiba A, Mohamed R, Rahmat R, et al. Ethnic differences in the prevalence of metabolic syndrome: results from a multi-ethnic population-based survey in Malaysia. PLoS One. 2012;7(9):46365. doi: 10.1371/journal.pone.0046365. [PubMed: 23029497].

13. Azimi-Nezhad M, Herbeth B, Siest G, Dade S, Ndiaye NC, Esmaily H, et al. High prevalence of metabolic syndrome in Iran in comparison with France: what are the components that explain this?. Metab Syndr Relat Disord. 2012;10(3):181-8. doi: 10.1089/met.2011.0097. [PubMed: 22283632].

14. Azizi S, Sadrzadeh Yeganeh H, Hosseini S, Ahmadi A, Daneshi Maskooni M, Safarpour M. Food Insecurity and some Associated Socioeconomic Factors Among Women with Metabolic Syndrome Referred to Clinics of Shiraz University of Medical Sciences. Armaghane Danesh. 2013;18(2):95-106.

15. Franz MJ. Medical nutrition therapy for diabetes mellitus and hypoglycemia of nondiabetic origin. Krause's food; 2004.

16. Darabi F, Rasaie N, Jafarirad S. The relationship between premenstrual syndrome and food patterns in university student girls. Jentashapir J Health Res. 2014;5(6).

17. Ghaderpour S, Baveicy K, Jafarirad S. Relationship of constipation and irritable bowel syndrome with food intake, anthropometric measurements and eating behaviors in male students. Nutr Food Sci Res.
2015;2(4):3-9.

18. Santos AC, Ebrahim S, Barros H. Gender, socio-economic status and metabolic syndrome in middle-aged and old adults. BMC Public Health. 2008;8:62. doi:10.1186/1471-2458-8-62. [PubMed: 18282285].

19. Park MJ, Yun KE, Lee GE, Cho HJ, Park HS. A cross-sectional study of socioeconomic status and the metabolic syndrome in Korean adults. Ann Epidemiol. 2007;17(4):320-6. doi: 10.1016/j.annepidem.2006.10.007. [PubMed: 17300958].

20. Mangat C, Goel NK, Walia DK, Agarwal N, Sharma MK, Kaur J, et al. Metabolic syndrome: a challenging health issue in highly urbanized Union Territory of north India. Diabetol Metab Syndr. 2010;2:19. doi: 10.1186/1758-5996-2-19. [PubMed: 20331871].

21. Ramsay SE, Whincup PH, Morris R, Lennon L, Wannamethee $\mathrm{SG}$. Is socioeconomic position related to the prevalence of metabolic syndrome?: influence of social class across the life course in a population-based study of older men. Diabetes Care. 2008;31(12):2380-2. doi: 10.2337/dc08-1158. [PubMed: 18809625].

22. Group HS. Healthy study rationale, design and methods: moderating risk of type 2 diabetes in multi-ethnic middle school students (2005). Int J Obesity. 2009;33(4):4.

23. Ford ES, Giles WH, Dietz WH. Prevalence of the metabolic syndrome among US adults: findings from the third National Health and Nutrition Examination Survey. JAMA. 2002;287(3):356-9. [PubMed: 11790215].

24. Storey $M$, Anderson P. Income and race/ethnicity influence dietary fiber intake and vegetable consumption. Nutr Res. 2014;34(10):84450. doi: 10.1016/j.nutres.2014.08.016. [PubMed: 25262170].

25. Kong A, Odoms-Young AM, Schiffer LA, Berbaum ML, Porter SJ, Blumstein L, et al. Racial/ethnic differences in dietary intake among WIC families prior to food package revisions. J Nutr Educ Behav. 2013;45(1):39-46. doi: 10.1016/j.jneb.2012.04.014. [PubMed: 23073175].

26. Sluyter JD, Schaaf D, Metcalf PA, Scragg RK. Dietary intakes of Pacific, Maori, Asian and European adolescents: the Auckland High School Heart Survey. Aust N Z J Public Health. 2010;34(1):32-7. doi: 10.1111/j.17536405.2010.00470.x. [PubMed: 20920102].

27. Yoo S, Nicklas T, Baranowski T, Zakeri IF, Yang SJ, Srinivasan SR, et al Comparison of dietary intakes associated with metabolic syndrome risk factors in young adults: the Bogalusa Heart Study. Am J Clin Nutr. 2004;80(4):841-8. [PubMed: 15447888]. 
Table 3. Mean (SD) Values of Food Intake (Serving/day) in Different Degrees of Education

\begin{tabular}{|c|c|c|c|c|c|c|}
\hline foods Erving/Day & Illiterate & Under Diploma & Diploma & Associate And Bachelor & Master and Above & PValue $^{\mathbf{a}}$ \\
\hline Rice & $5.9 \pm 4.3$ & $6.2 \pm 3.6$ & $7.2 \pm 4.3$ & $6.6 \pm 4.3$ & $5.1 \pm 2.5$ & 0.592 \\
\hline Pasta & $0.8 \pm 1$ & $1.0 \pm 1.1$ & $1.4 \pm 2.1$ & $1.3 \pm 1.5$ & $1.1 \pm 1.6$ & 0.572 \\
\hline Bread & $6.6 \pm 4.0$ & $7.9 \pm 7.4$ & $9.1 \pm 7.5$ & $7.8 \pm 6.5$ & $4.3 \pm 2.4$ & 0.380 \\
\hline Meat & $0.4 \pm 0.4$ & $1.0 \pm 1$ & $1.1 \pm 1$ & $1.2 \pm 1.2$ & $1.2 \pm 0.5$ & 0.067 \\
\hline Chicken & $1.0 \pm 1$ & $1.4 \pm 1.5$ & $1.3 \pm 1.2$ & $1.6 \pm 1.5$ & $1.6 \pm 1.2$ & 0.495 \\
\hline Fish & $0.6 \pm 0.6$ & $0.8 \pm 0.9$ & $0.4 \pm 0.5$ & $0.7 \pm 0.9$ & $0.7 \pm 0.4$ & 0.31 \\
\hline Egg & $0.5 \pm 0.5$ & $0.4 \pm 0.4$ & $0.6 \pm 0.7$ & $0.5 \pm 0.6$ & $0.6 \pm 0.6$ & 0.594 \\
\hline Legume & $0.5 \pm 0.9$ & $0.7 \pm 0.6$ & $0.7 \pm 0.8$ & $0.8 \pm 1.1$ & $0.5 \pm 0.3$ & 0.792 \\
\hline Milk & $0.24 \pm 0.5$ & $0.47 \pm 0.5$ & $0.56 \pm 0.7$ & $0.46 \pm 0.6$ & $0.6 \pm 0.5$ & 0.488 \\
\hline Yogurt & $0.36 \pm 0.4$ & $0.58 \pm 0.7$ & $0.4 \pm 0.4$ & $0.59 \pm 0.5$ & $0.68 \pm 0.6$ & 0.271 \\
\hline Doogh & $0.43 \pm 0.6$ & $0.32 \pm 0.4$ & $0.46 \pm 0.8$ & $0.51 \pm 0.7$ & $0.28 \pm 0.2$ & 0.421 \\
\hline Ice cream & $0.19 \pm 0.4$ & $0.16 \pm 0.2$ & $0.21 \pm 0.3$ & $0.29 \pm 0.5$ & $0.06 \pm 0.1$ & 0.142 \\
\hline Cheese & $0.78 \pm 0.7$ & $0.76 \pm 0.8$ & $0.91 \pm 1.1$ & $1.0 \pm 1.2$ & $0.82 \pm 0.7$ & 0.701 \\
\hline Fruits & $2.2 \pm 3.1$ & $0.8 \pm 1.5$ & $1.1 \pm 1.2$ & $0.8 \pm 1.2$ & $0.7 \pm 1.1$ & 0.22 \\
\hline Vegetables & $1.5 \pm 1.7$ & $0.4 \pm 0.8$ & $0.3 \pm 0.6$ & $0.4 \pm 0.6$ & $0.6 \pm 0.9$ & $0.001^{\mathrm{b}}$ \\
\hline Pizza & $0.1 \pm 0.3$ & $0.2 \pm 0.3$ & $0.3 \pm 0.9$ & $0.4 \pm 1.1$ & $0.2 \pm 0.4$ & 0.369 \\
\hline Sausage & $0.1 \pm 0.3$ & $0.3 \pm 0.5$ & $0.2 \pm 0.3$ & $0.3 \pm 0.6$ & $0.1 \pm 0.2$ & 0.378 \\
\hline Falafel & $0.3 \pm 0.5$ & $0.6 \pm 0.9$ & $0.5 \pm 0.8$ & $0.6 \pm 1$ & $0.2 \pm 0.2$ & 0.728 \\
\hline Soda & $0.3 \pm 0.4$ & $0.4 \pm 0.9$ & $0.7 \pm 1.8$ & $0.9 \pm 1.7$ & $0.3 \pm 0.4$ & 0.237 \\
\hline Cake and sweet & $0.6 \pm 0.5$ & $0.8 \pm 1$ & $0.7 \pm 1.3$ & $0.8 \pm 1$ & $0.5 \pm 0.3$ & 0.840 \\
\hline Chocolate and candy & $0.3 \pm 0.8$ & $0.8 \pm 1.4$ & $0.8 \pm 1.9$ & $1.1 \pm 1.9$ & $0.4 \pm 0.4$ & 0.528 \\
\hline
\end{tabular}

a One- way ANOVA

${ }^{\mathrm{b}}$ Significance level $<0.05$ 
Table 4. Mean (SD) Values of Food Intake (Serving/day) in Different Jobs

\begin{tabular}{|c|c|c|c|c|c|c|}
\hline Foods Serving/Day & Jobless & Worker & Employee & High-Ranking Employee & Self-Employed & PValue $^{\mathbf{a}}$ \\
\hline Rice & $6 \pm 4.3$ & $5.3 \pm 2.8$ & $6.7 \pm 4$ & $5.8 \pm 2.8$ & $7 \pm 3.9$ & 0.550 \\
\hline Pasta & $1.2 \pm 1.3$ & $1.8 \pm 1.3$ & $1.0 \pm 1.2$ & $1.0 \pm 1.4$ & $1.2 \pm 2.0$ & 0.558 \\
\hline Bread & $6.9 \pm 5.0$ & $6.4 \pm 3.7$ & $7.8 \pm 7.2$ & $5.6 \pm 4.6$ & $9.3 \pm 8.1$ & 0.314 \\
\hline Meat & $1.0 \pm 1.1$ & $0.7 \pm 0.5$ & $1.0 \pm 0.9$ & $1.0 \pm 0.8$ & $1.2 \pm 1.3$ & 0.586 \\
\hline Fish & $0.5 \pm 0.5$ & $0.6 \pm 0.7$ & $0.8 \pm 0.9$ & $0.4 \pm 0.2$ & $0.7 \pm 0.9$ & 0.245 \\
\hline Egg & $0.5 \pm 0.5$ & $0.4 \pm 0.3$ & $0.5 \pm 0.5$ & $0.7 \pm 0.8$ & $0.5 \pm 0.6$ & 0.820 \\
\hline Legume & $0.6 \pm 0.8$ & $0.8 \pm 0.7$ & $0.8 \pm 0.1$ & $0.5 \pm 0.4$ & $0.6 \pm 0.7$ & 0.705 \\
\hline Milk & $0.48 \pm 0.6$ & $0.3 \pm 0.3$ & $0.43 \pm 0.5$ & $0.52 \pm 0.3$ & $0.53 \pm 0.7$ & 0.767 \\
\hline Yogurt & $0.55 \pm 0.7$ & $0.4 \pm 0.3$ & $0.58 \pm 0.5$ & $0.67 \pm 0.3$ & $0.5 \pm 0.3$ & 0.795 \\
\hline Doogh & $0.4 \pm 0.5$ & $0.44 \pm 0.4$ & $0.45 \pm 0.8$ & $0.35 \pm 0.4$ & $0.44 \pm 0.5$ & 0.984 \\
\hline Ice cream & $0.29 \pm 0.5$ & $0.2 \pm 0.2$ & $0.2 \pm 0.3$ & $0.08 \pm 0.1$ & $0.2 \pm 0.2$ & 0.504 \\
\hline Cheese & $0.9 \pm 0.9$ & $1.1 \pm 1.2$ & $0.9 \pm 0.9$ & $0.7 \pm 0.3$ & $0.8 \pm 1.2$ & 0.801 \\
\hline Fruits & $1.1 \pm 2.0$ & $0.3 \pm 0.5$ & $0.7 \pm 1.3$ & $1.0 \pm 1.2$ & $1.1 \pm 1.8$ & 0.336 \\
\hline Vegetables & $0.5 \pm 0.9$ & $0.2 \pm 0.3$ & $0.4 \pm 0.8$ & $0.8 \pm 0.8$ & $0.6 \pm 0.8$ & 0.423 \\
\hline Pizza & $0.14 \pm 0.2$ & $0.1 \pm 0.2$ & $0.2 \pm 0.7$ & $0.4 \pm 0.4$ & $0.6 \pm 1.3$ & 0.056 \\
\hline Sausage & $0.3 \pm 0.7$ & $0.3 \pm 0.3$ & $0.2 \pm 0.4$ & $0.1 \pm 0.1$ & $0.3 \pm 0.4$ & 0.816 \\
\hline Falafel & $0.7 \pm 0.9$ & $0.7 \pm 1.5$ & $0.4 \pm 0.8$ & $0.2 \pm 0.2$ & $0.5 \pm 0.8$ & 0.363 \\
\hline Soda & $0.7 \pm 1.5$ & $0.6 \pm 1.8$ & $0.5 \pm 0.9$ & $0.3 \pm 0.4$ & $0.8 \pm 1.7$ & 0.630 \\
\hline Cake and sweet & $0.6 \pm 0.7$ & $1.4 \pm 1.7$ & $0.7 \pm 0.9$ & $0.3 \pm 0.2$ & $1.0 \pm 1.2$ & $0.021^{b}$ \\
\hline Chocolate and candy & $1.0 \pm 1.8$ & $1.0 \pm 2.0$ & $0.6 \pm 1.2$ & $0.6 \pm 0.4$ & $1.0 \pm 2.0$ & 0.673 \\
\hline
\end{tabular}

${ }^{a}$ One-way ANOVA.

${ }^{\mathrm{b}}$ Significance level $<0.05$. 
Table 5. Mean (SD) Values of Food Intake in Different Ethnicities

\begin{tabular}{|c|c|c|c|c|c|c|}
\hline Foods Serving/Day & Lor, Lak, Bakhtiyari & Turk & Kurd & Arab & Persian & PValue $^{a}$ \\
\hline Rice & $7.1 \pm 4.3$ & $5.7 \pm 4.4$ & $4.4 \pm 1.6$ & $6.4 \pm 3.9$ & $6.0 \pm 3.5$ & 0.318 \\
\hline Pasta & $1.4 \pm 1.7$ & $1.2 \pm 1.6$ & $0.7 \pm 0.6$ & $1.1 \pm 1.6$ & $0.8 \pm 0.9$ & 0.295 \\
\hline Bread & $6.1 \pm 4.1$ & $8.2 \pm 5.6$ & $10.1 \pm 15.1$ & $10.8 \pm 8.1$ & $5.0 \pm 3.1$ & $0.001^{b}$ \\
\hline Meat & $1.2 \pm 1.2$ & $1.4 \pm 1.0$ & $1.7 \pm 1.5$ & $0.9 \pm 0.7$ & $0.9 \pm 1.2$ & 0.118 \\
\hline Chicken & $1.5 \pm 1.2$ & $1.9 \pm 1.6$ & $1.9 \pm 2.3$ & $1.5 \pm 1.6$ & $1.1 \pm 1.0$ & 0.235 \\
\hline Fish & $0.5 \pm 0.6$ & $0.7 \pm 1.1$ & $0.3 \pm 0.1$ & $1.0 \pm 1.0$ & $0.5 \pm 0.5$ & $0.005^{\mathrm{b}}$ \\
\hline Egg & $0.4 \pm 0.4$ & $0.7 \pm 0.5$ & $0.4 \pm 0.3$ & $0.6 \pm 0.6$ & $0.4 \pm 0.5$ & 0.296 \\
\hline Legume & $0.8 \pm 1.0$ & $0.9 \pm 0.9$ & $0.3 \pm 0.2$ & $0.7 \pm 0.9$ & $0.5 \pm 0.6$ & 0.173 \\
\hline Milk & $0.4 \pm 0.4$ & $0.5 \pm 0.4$ & $0.3 \pm 0.4$ & $0.5 \pm 0.7$ & $0.5 \pm 0.6$ & 0.677 \\
\hline Yogurt & $0.5 \pm 0.4$ & $0.5 \pm 0.6$ & $0.4 \pm 0.5$ & $0.5 \pm 0.4$ & $0.7 \pm 0.8$ & 0.4 \\
\hline Doogh & $0.46 \pm 0.6$ & $0.7 \pm 0.7$ & $0.2 \pm 0.3$ & $0.4 \pm 0.6$ & $0.4 \pm 0.7$ & 0.521 \\
\hline Ice cream & $0.23 \pm 0.4$ & $0.4 \pm 0.5$ & $0.2 \pm 0.3$ & $0.2 \pm 0.3$ & $0.2 \pm 0.3$ & 0.648 \\
\hline Cheese & $0.97 \pm 1.2$ & $1.2 \pm 1.2$ & $1.1 \pm 0.7$ & $0.8 \pm 0.8$ & $0.8 \pm 1$ & 0.488 \\
\hline Fruits & $0.9 \pm 1.4$ & $1.8 \pm 3.5$ & $0.7 \pm 1.0$ & $0.8 \pm 1.6$ & $1.0 \pm 1.5$ & 0.463 \\
\hline Vegetables & $0.3 \pm 0.5$ & $0.6 \pm 0.7$ & $0.3 \pm 0.4$ & $0.5 \pm 0.8$ & $0.8 \pm 1.2$ & 0.042 \\
\hline Pizza & $0.2 \pm 0.3$ & $0.2 \pm 0.4$ & $0.1 \pm 0.07$ & $0.4 \pm 1.2$ & $0.3 \pm 0.9$ & 0.470 \\
\hline Sausage & $0.2 \pm 0.5$ & $0.4 \pm 0.4$ & $0.2 \pm 0.1$ & $0.3 \pm 0.5$ & $0.2 \pm 0.5$ & 0.764 \\
\hline Falafel & $0.4 \pm 0.6$ & $0.3 \pm 0.3$ & $0.6 \pm 0.6$ & $0.7 \pm 1.0$ & $0.6 \pm 1.0$ & 0.386 \\
\hline Soda & $0.5 \pm 0.8$ & $0.4 \pm 0.6$ & $2.3 \pm 4.4$ & $0.5 \pm 1.0$ & $1.0 \pm 1.8$ & $0.006^{\mathrm{b}}$ \\
\hline Cake and sweet & $0.6 \pm 0.7$ & $1.4 \pm 1.9$ & $0.3 \pm 0.2$ & $0.8 \pm 1.0$ & $0.8 \pm 1.2$ & 0.09 \\
\hline Chocolate and candy & $0.6 \pm 1.0$ & $0.5 \pm 0.6$ & $2.3 \pm 4.4$ & $0.7 \pm 1.4$ & $1.4 \pm 2.1$ & $0.012^{\mathrm{b}}$ \\
\hline
\end{tabular}

${ }^{a}$ One-way ANOVA.

${ }^{\mathrm{b}}$ Significance level $<0.05$. 